\title{
Place of the didactic literature in Vahshi Bafghi's Khold-e-Barin
}

\author{
Seied Mohammad Bagher Kamaladdini \\ Department of Persian Literature and Language, Payame Noor University, Tehran, Iran \\ E-mail address: kamaladdini@pnu.ac.ir
}

\begin{abstract}
Masnavi Khold-e-Barin is one of letters that educate people moral courses in different ways. Vahshi Bafghi by using his special technique, compose a word full of advice and using the different metaphor sings helps to understanding of good and bad issues in life. He expresses ethical messages in two ways, the theme of novel and direct expression. This paper tries to evaluate the Place of the educational literature in Vahshi Bafghi's Khold-e-Barin; the author shows aspects and features of didactic literature using content analysis in Khold-e-Barin. Issues such as the avoidance of envy, greed, worldly and other worldly courses, advice and the moral results of tales, praised of the knowledge and awareness, chastity word of poet, give didactic Ethics and Spirituality atmosphere to this letter. In this research, didactic poems in two sections of "sermon - ethical" and "Education - Spiritual" have been studied.
\end{abstract}

Keywords: Khold-e-Barin; didactic literature; moral poetry; mystical poetry

\section{INTRODUCTION}

Iranians always had a particular interest to didactic literature according left letters of preIslamic era. Most important parts of Pahlavi literature are Andarz-Nameha. These Andarz Nameha usually has written in simple language using similes and metaphors in a form of negotiations between the King and the Wise or several Wise (Tafazoli, 2000:206). There are traces of pre-Islamic period didactic literature in literature od Islamic period such as "ayeein namak" book which is A set of moral and cultural traditions, grief customs, combat, joy and etc. teachings that many writers of Islamic period have used it in their works (Bahar, 2003:50). Many of these didactic works were translated into Arabic during the Islamic period, and its Pahlavi version has disappeared; like the book of "Javidan Kherad (eternal wisdom)" that Ebn Moskooye translated into Arabic and other works that Ebn Moghfeh translated to Arabic. Didactic works of Islamic" is describe a knowledge to the reader describes or presented moral, religious and philosophy courses in the form of literature "(Shamisa, 2004:27).

This method is more salient in the Islamic period "After the arrival of Islam in Iran, Iranian writers adopted Islamic culture and developed this regard in their ethical works and less their link with the Iranian ancient idea gradually" (Khorasani, 2008:13). It should be noted that some Persian books in early Islamic period which were considered the ethical and moral teachings directly or indirectly, the educational teachings of ancient Persia such as description 
of drinking wine, necessity divine splendor, Having a royal lineage to King, Avenge and ... were emphasized but by passing the time and gradually the issues were mismatch to Islamic rules were omitted and new issues such as Ayat and Ahadis and Islamic rules and concepts are reflected.

What was the didactic literature reason of prosperity and stability is the formation of the mysticism in Iranian culture and Mystics were withdrawal from the world and guide people to instability of world, transient the pleasures and it's sorrows; so mysticism has biggest portion in Iranian didactic literature. It's Not unpleasant to note that the didactic poem which in past, including the ethical, religious and mystical, the political and social issues entered in it after Mashroote Revolution and makes it rich and leads it to the commitment and social issues (Razmjoo, 1995:79). Among mystic poets witch is related to past Persian literature are two separate categories that include: "didactic poetry and lyric poetry", although there are some works of some of the ancient Sofia in Both categories, the most comprehensive works are from three mystics of Khorasan: Sanayee; Attar and Rumi; in didactic poetry witch offered in the form of Masnaviat and the lyric poetry witch offered in form of Ghazaliat and Ghalandariat (Zarrinkoob, 2001:330).

\section{ETHICS IN MASNAVI OF KHOLD-E-BARIN}

Kamal-din Maulana Mohammad Vahshy bafghy is one of the leading poets of the tenth century of Persia that born in in the city Bafgh at the year 939 AH (Nakhaee, 1987:15). His life was coincided in Shah Ismail II of Safavi, Shah Tahmasp and Shah Mohammad Khodabandeh. In a period of time that Vahshi Bafghi could give a new spirit to the patient literature of his time with his sweet poems Persian poetry and literature was fighting with different illness and inabilities. Effects of Bloodthirsty predators of Moghol And then marauding Turks of teimori and their survivors has significant appearance in that time which Persian poetry were very difficult and complicated and confusing by different motivation. Indian settlers and the Indian turnovers were wandering Persian literature readers and audiences by unselfishness and word play and create hard words and combinations in Safavieh period, (Nakhaee, 1987:90). Vahshi Bafghi was one of the few shining stars in this turbulent times and difficult teller's market that draw invalidity line on poets of his time and step in the friendly way of Rudaki and Ferdowsi and Farouki were gone hundreds of years ago. This sweet eloquent of language rebuilds the old doctrine of Persian literature by simple saying and modernization and simplicity and fluency (the same). His surviving works include: poetry Divan, Masnavi Kholde-Barin, Masnavi Nazer and Manzoor and masnavi Farhad and Shirin.

Among these works the Masnavi Kholde-Barin is considered as didactic works of Persian literature. therefore should be said that:

"If literature is borne of art hunter and art grower of human nature and the respect that the literature will reach to peak of its art and beauty when this visual arts accompanied with an internal commitment of its creator, consequently, we come to the conclusion that the greatest type of literature is a kind that transmitter of this is internal commitment and has a broader and more profound impact than the of superficial harmonics enjoy morphological effect which is the pleasure that born from intellectual and spiritual punishment and vicissitude of audience" (Momtahen, 131:2011). 
In fact that literature is a literature when reach noble achievement, which is educating communities and generations (Rak, Hosseini Halleh, 2006:6). Vahshi composed this Masnavi following the Nezami, on the weight of the Makhzan Asrar and in eight part. Vahshi words of the Masnavi, as Aristotle sais in Poetics, says is not ever empty by fabulous theme and this is essential needs of poem that nature of poetry of imagination create a world Apart from the real world into the allegory of poet and puts it in front of the real world (Sarfi, 2011:109).

\section{EXPRESSING WAY OF MESSAGE IN MASNAVI KHOLD-E-BARIN}

\section{1. Direct Teachings at the start and end stories}

Ethical teachings of Rumi are presented in two ways, Vahshi sometimes says at the beginning of the Masnavi with direct messages and in midst of his words and at the end of the story as conceptual conclusion and sometimes with indirect method and help of telling his stories to pass the message to the reader. Sometimes these direct messages target is Vahshi himself:

What is the benefit of this Homelessness?

What is from this destination and what is the purpose?

For whom build the mud in front of home door

To not to be embarrassed in front of others

(Divan, 1984: p. 393).

Sometimes, addresses the general audience and addressed the man his ethical thought :

Give gold and buy friends talks

What is cooler that give gold for gold

That you know the losses from enemy

Is better to take friendship from bad people

(the same, p 405).

\section{2. Indirectly Teachings in theme Stories}

Using stories and anecdotes in order to encourage the audience to read and accepting the issue, and finally acting it is one of Vahshi Bafghi tricks on Masnavi Khold Barin that uses In order to attract the reader's attention and delight the senses and influence the audience; because the story and the tale and allegory of past in view of pleasure, affecting, make simple and understandable the meaning and understanding to the level of education of the respondent. should mention that this method (the use of stories and anecdotes) began with Hadiqhe Sanai, continued by Attar Masnavis and Molavi Culminate it in Masnavi Manavi. Vahshi uses stories and narratives, with the full knowledge and as a witness to prove his ideas and ethical and mystical thoughts. Ideas expression way is in expected range of reader. Vahshi convey the Story in determine and intended path. in other words we can say that Vahshi looks at stories as a tool (in this work), stories that we are facing at end with a or some moral, mystic or religious conclusion.

\section{2. 1. Sermon - ethical Poems}

Vahshi Bafghi has been introduced a clear moral system according to his mindset. We declare a part of these ethical poems in this paper. The Method is selecting a title for each poem along with an explanation and suffice to have a couple of examples. then continue to we said 
the influence of some Kholde- Barin beats from verses of the Quran ,since the base work is showing sample of Vahshi's words and ideas in mentioned titles. Kholde- Barin at the beginning of the book is full of names of God. Vahshi declare achieving the grace of god's treasure as the basic purpose of his lives that his quest for this kind of account is the first stage of the journey to god.

\section{Counsel of God}

Vahshi believes that the counsel of God is applied in all things and works of human life, and believes this is sometimes not understood by humans. The following beat In addition of the creation refers to hide wisdom of God:

If there is not Iron lather

How the stone become idol of idols lather

If idols lather won't use hatchet

Cannot figure the idols body!

(The same., p 391)

\section{All the world are available for man and his Authority}

Vahshi according his worldview is on the belief that man was created as the the aime of creation and is the cornerstone of all existence, the god created all existence providing for him:

The steering wheel is under your command

Globe ball is on your Polo stick bend

$\mathrm{He}$ is putting his hands on your Horse Saddle

The universe altar comes to your soil

(The same., p 393)

\section{Arise and won't be worry for passing world}

Recommendation to be living happy, looking in real manner to the world of our sorrow, Avoiding from inconsequent sorrow, and in simple words Appreciate the chances can be seen in most of poet's poetry. Vahshi often made his audience to thinking that feeling sad result is nothing except inconsequent:

Don't eat all of these sorrows of the world

The world hardship will be passed, won't bed sad

A Grief is eggs of countless grief

The testis of a snake makes a countless snake

The doors of all the tears you benefit

What is benefit that not you are not fun?

(The same., p 402)

\section{Stay away from self-pride and arrogant}

The self-pride is considered one of most worst characteristic of human traits. In some passages the word arrogant is clear; verses that introduce arrogant position on Hell (Nahl: 29, Zumar: 60, 72; Ghafer: 76), Vahshi Bafghi found the point of Quranic guidelines that the stem of lots of sins is self-pride and not give up to right (god) and a human without the humble is useless creature that his not-being is better than being. 
You, who is Flag Hoisting of self-pride

Putting down the humble crown from your head

Who is not beneficent from this crown!

It's better to don't be born at all

(The same. p 405)

\section{Contentment}

Vahshi Declare if you want to be content, you should set contentment on top of your signboard in the life. Vahshi is a catholic and benevolence man who is convinced with a leaf. It's his sublime contentment which made him noble and free and compose all over his speeches (poems), like Saadi: "contentment make the people rich":

Chinese fawn is good breathing of eating just leaves

Copper that become gold with panacea is the effect of plant leaves Until when you suffer from the blood of lust, if there is no bread be contentment with the plant (life).

(The same., p. 409)

\section{Avoiding the lust}

This Condemned attribute which cause other moral vices such as oppression, ignorance of God and , mixing of right and wrong due to its nature is blamed in almost all of the didactic letters and the poets warned the human from this condemned quality:

You are not ant what is the back of this lust?

You are not the, what is this open mouth?

The grave that put soil into it, because it was demanding morsel.

Who the lust is not being far from him, it's better to be a morsel for grave.

(The same., p 409)

\section{The world, the Punishment place}

These poetry beats draw it with a beautiful admonition:

Do not do the bad works to others, fear from the rotation of times.

The time do the punishments, Fear from it.

Who is farming in this field, earn seed as he farmed before.

Whoever do the bad works don't receive except the bad works that he did.

(The same, p 413)

\section{Humility}

Humility attribute has such effect on human behavior that affects the health of the soul. Vahshi like Saadi believe that: "the pure God create you from the soil ...":

Be the soil of people way,

Be humiliated as the characteristic of the soil.

Soil characteristic select the humility

You are the soil and won't be something else from soil.

(The same., p 405) 


\section{Advice to be artist}

Among the motifs of Vahshi poetry in Khold-e-Barin is attention and recommendations to be artist., among his poem beats he says priding to the person lineage does not have any benefit for people. The man advantage is his personal art and the science that cause liberation of human from the clutches of his stupor:

You are talking about your father's ascendancy!

Show yourself and the arts that you have

The candle that gives smoke

Light the house and the black the other.

(The same., p 407)

\section{Advice to be silent}

By the mystic opinion, the silence leads to hide one's flaws and bad traits in many cases. Vahshi knows the talkative people as their Scourge and describes this with a beautiful allegory:

Put the silence stamp on own lips,

It cause didn't reveal your vulgarity.

(The same, p 399)

\section{Avoiding the semblance and hypocrisy piety.}

In revisory opinion of Vahshi hypocrisy has no place and is contract with honesty. Vahshi warned us of the hypocrisy and says with beautiful analogy that culturing the lies does not load truth:
Although the bear will be long extremely
Long bears is not making the point
the base won't be high by this theme
The goat has a big one too.
(The same, p 399)

\section{2. 2. Didactic - Mystic Poems}

Despite the mystical poetry considered as Ghanaei literature, but also can be considered as didactic poetry as well, because "Sufi literature is often the aspect of education and edification." (Behzadi, 372: 2000). In the following there is a part of Khold Barin beats that have didactic aspects mixed with mysticism terminology.

\section{Seclusion}

This recommendation of seclusion from the world and worldly desires can be considered as a deriving from the Sufi's teachings, and in a more detailed look as an effect Attar on Vahshi:

Don't show your face to people like angles

That makes you sad with magic

Be away from tis curtain rifting people

Be at the back of curtain like the eye light.

(The same, p 392) 


\section{Trying to live happy!}

Hey! The embodied sadness

if happiness sees you will be sad

Don't be sad for this world

The world sadness will be passed, don't be upset.

(The same, p 402)

\section{Can reach to the purpose with the grace of God}

A glance from one hearted people

Will be the guidance of your way for hundred years,

the help of glance from hearted people,

Is opening a door in purpose face.

(The same, p 414)

\section{CONCLUSIONS}

In addition that Vahshi use to the mystical terms and interpretations, he sometimes of the ethics, journey and moral discussion in content. In Vahshi Bafghi's educational model the human being is the noblest and most sacred creatures of the universe, and therefore he, himself that only can be change his own fate prosperity or adversity.

Vahshi in addition of stating mystical teachings the recommend Self-analysis and is awaiting help of God. the investigation in Khold-e-Barin makes it clear that He is well acquainted with the Quranic culture and teachings and use many words, concepts and meanings of the Qur'an in his poetry but since in some cases has used only limited connote, Identifying of the verse requires special finesse and precision.

\section{References}

[1] Bahar Mohammad Taghi (1961). Stylistics -Sabk shenasi- (on the evolution of Persian prose), Tehran: Amir Kabir

[2] Behzadi Hussein (2000). Humor and satiric in Iran, Tehran: Saduq

[3] Tafazoli Ahmed (2000). The pre-Islamic literature, with attempts of Jaleh Amoozegar, third edition, Tehran: Sokhan.

[4] Tamimdari Ahmad (2001). Book of Iran (Persian literary history, schools, courses, literary styles), Tehran: Huda.

[5] Hosseini Halle, Seyed Mohsen (2006). An introduction of educational literature, Etelaat newspaper, No. 23642.

[6] Khorasani Mahboobe (2008). Discussions of ethics and moral status Jalali, literary research, Year 5, Issue 20.

[7] Dehkhoda Ali Akbar (1999). Dictionary, under Mohammed Moein and Seyed Jafar Shahidi, Tehran: Tehran University.

[8] Razmjoo Mohsen (1995). A variety of literary works in Persian, Mashhad: Astan Quds Razavi. 
[9] Zarrinkoub Abdol Hosein (1999). Than anything else, Tehran: Sokhan.

[10] Shafiei Kadkani, Mohammad Reza (1973). Types of literature in Persian poetry, Kheradva Kooshesh journal, Shiraz university, fourth set, third edition.

[11] Shamisa Siroos (2004). Variety of literary, Tehran: Ferdos

[12] Sarfi, Mohammad Reza and Esfandiari, Mahsa.. (2011). Didactic Poems of Attar, Didactic Literature Research, Third Year, No. XII, p 126-103.

[13] Musharraf Maryam (1966). Didactic theory of Nasser Khosrow in Roshanaeinameh Masnavi, Gohare Gooya Research Journal, No. 5.

[14] Mohsen Nia, Naser, Barzegare Khaleghi, Muhammad Reza, Noor Zadeh Chegini, Vhideh (1390). A Research in didactic literature Role in Persian Literature, Didactic Research Journal, Third Year, No. 10, p 122-103.

[15] Momtahen Mahdi, Mohamadi GerdAfarin (1969). Parvin Etesami in didactic, literature, Didactic Literature Journal, Third Year, No. 10.

[16] Nakhaee Hussein (1366). Vahshi Bafghi Divan, Seventh Edition, Tehran: Sepehr.

[17] Ayoob Moradi, Mahmoud Kamali, Sara Chalak, Hooshang Izedi, International Letters of Social and Humanistic Sciences 13 (2014) 32-51.

[18] Mohammad Baqere Kamaladdini, Morteza Ghiasi, International Letters of Social and Humanistic Sciences 15(1) (2014) 22-30.

[19] Seyed Mohammad Bagher Kamaladdini, International Letters of Social and Humanistic Sciences 15(2) (2014) 119-124. 